\title{
DETERMINATION OF HYDRODYNAMIC POWER LOSSES IN A GEARING
}

\author{
Valerii STAVYTSKYI*, Oleksandr BASHTA ${ }^{* *} \oplus$, Pavlo NOSKO** ${ }^{*}$, Yurii TSYBRI $^{* * *} \oplus$ \\ "Educational and Scientific Institute of Transport and Building, Volodymyr Dahl East Ukrainian National University, \\ Tsentralnyi ave., 59-a, 93400, Severodonetsk, Ukraine \\ *Department of Applied Mechanics and Materials Engineering, Aerospace Faculty, National Aviation University, \\ Lubomyr Husar ave., 1, 03058, Kyiv, Ukraine \\ ${ }^{* *}$ Faculty of Mechanical Engineering, Bialystok University of Technology, \\ Wiejska st., 45C, Bialystok, 15-351, Poland
}

friction.pairs@ukr.net, nosko_p@ukr.net, oleksandr.bashta@npp.nau.edu.ua, tsybriii@ukr.net

received 4 July 2021, revised 17 September 2021, accepted 25 September 2021

\begin{abstract}
Despite the relatively numerous experimental studies, there are few published works on the topic of development of mathematical models that describe the hydrodynamic processes in gears. There is no generic analytical model that integrates all types of losses. The purpose of this work is to develop a modern generalised methodology for calculating the hydrodynamic power losses of high-speed gears. For each gear, partially or fully immersed into an oil bath, the power spent to overcome the hydromechanical resistance can be represented as the sum of the following: the Coriolis force moment arising from the radial movement of the oil in the tooth spaces of the rotating gear, the viscous friction forces moment on the periphery of the gear addendums in the oil bath and the viscous friction forces moment at the face of the gear in the oil bath. The hydrodynamic power losses due to the Coriolis force action, viscosity friction losses at the periphery of the gear and the viscosity friction at the face of the gear (both turbulent and laminar modes) were observed separately. From the mathematical simulation of the rotation processes when the gear is immersed into the oil bath, an analytical dependence was obtained. It allows predicting the influence of the geometrical parameters of the gearing on the hydrodynamic power losses. Analysis of the calculation results of the power losses due to the action of hydraulic resistance forces and results from experimental studies is provided for several gears with different hydromechanical parameters. The proposed method of calculating power loss due to hydromechanical resistance of the oil bath to the rotation of the gear gave results that were close to the experimental data. Acceptable coincidence of theoretical and experimental results allows recommending the received analytical dependencies for practical calculations of high-speed gears.
\end{abstract}

Keywords: hydrodynamic power losses, gearing, tooth spaces, high-speed gears, Coriolis force, mathematical model

\section{INTRODUCTION}

The current state of research on gear trains can be said to be evolving in several directions. One of them is development of the geometry of new gearings based on the classic geometric and kinematic theories of gearing developed by, for instance, Bolotovskiy, 1974 [6] and Litvin, 1968 [27]-[29] and expanded by, for instance, Shishov, 2001 [37], Karpov, 2017 [24], Tkach, 2018 [43 44] and Franulovic et al., 2017 [18]. Besides, Hlebanja, 2012 [20] proposed an alternative S-gear tooth geometry, which improves the contact circumstances by lowering the contact pressure, which consequently enables the thickening of the oil film, diminishes the amount of sliding and thus lowers friction. Kapelevich, 2000 [23] presented a method of research and design of gears with asymmetric teeth that enables increases in the load capacity and reduction of the weight, size and vibration level. Litvin 2002 [30] investigated and compared two versions of face-gear drives based on the application of a spur pinion of two versions of geometry and conjugated face gear. The following advantages were obtained with the new version of geometry: (i) longitudinal orientation of bearing contact, which enables avoidance of the edge contact; and (ii) reduction of contact stresses.

The other direction is the study of the stressed state of gear teeth to develop the most reliable analysis of the strength (Resh- etov, 1989 [35]; loselevich, 1988 [22], Litvin, 2002 [30]), for instance. Senthil Kumar, et al., 2008 [25] presented the optimisation of the asymmetric spur gear drive, which was carried out by using an iterative procedure on the calculated maximum fillet stresses through finite element method (FEM) for different rack cutter offsets, and finally, the optimum values of rack cutter offsets are suggested for the given centre distance and the speed ratio of the asymmetric gear drive.

One more direction of gear train research is improvement of the existing synthesis techniques of gear drives by designing gearings on the basis of optimisation models (Chen et al., 2016 [12], Zhuravlev, 2001 [45], Chen et al., 2019 [11], Fong et al., 2002 [17] and Gao et al., 2002 [21]) and B-spline curves, interpolating a number of discrete points on involute profiles. In this case, tooth surfaces are modelled by sweeping the B-spline profiles along user-defined trajectories (Barone, 2001 [4]). Besides, a mathematical model of the helical spur gear under condition of gear non-undercutting, as well as the software to generate the complete geometry of a gear, including the involute tooth surfaces, the modified root fillets and the modified tip fillets, has been developed by Chen and Tsay [10], using experimental studies of the teeth tense state in order to refine the existing calculation methods.

Amania et al., 2017 [3] performed an independent investigation of tip pointing and undercutting conditions. A non-dimensional 
methodology was introduced, and the order of the multiparametric problem was reduced. This model took into account all applicable geometric and kinematical conditions and constraints to qualify each point in the design space (hence each combination of geometrical gear design parameters) in terms of manufacturability and geometrical compatibility.

Increase in transmitted capacities and speeds causes considerable energy dissipation and, as a consequence, an increase in the temperature in a gearing. This impairs the mechanical characteristics of gear drive parts and reduces their service life. As a generalised criterion of the effectiveness of high-speed gear drive, the efficiency of a gearing can be considered, taking into account the conditions and modes of operation, materials and manufacturing process, transmitted load and peripheral speed.

Power losses can be conditionally divided (Niemann, 2003 [32]) into those that depend on the transmitted load (mechanical friction in a gearing and bearings) and those that are independent of the load (aero-hydrodynamic resistance, periodic compression and expansion between teeth) (Changenet, 2006 [9], 2007 [7], 2008 [8], Seetharaman et al., 2009 [36], Zhouet al., 2014 [46], Polly et al., 2017 [34]). An exhaustive study of different kinds of power loss distributions was conducted by Heingartner (2005) [19] and Lechner and Naunheimer [26].

In the study of hydrodynamic resistance while immersing gears into an oil bath, most authors have developed empirical equations to determine the dimensionless moment coefficient of hydrodynamic resistance (Mann, 1961 [31]) and considered a rotor, disc or gear immersed into the oil bath. In addition, Ahsan (2016) [1] investigated this phenomenon of hydrodynamic power dissipation in elastic systems (discs) oscillating in viscous fluids, which may provide a viable means for reducing energy losses.

Based on the results of experiments, Daily et al., (1960) [14] proposed the consideration of four modes of flow around a disc that is completely immersed into a liquid.

The phenomena occurring in the area between the teeth were considered by Akin et al. (1975) [1]. They proposed a vector model for estimating the depth of oil filling in rotating gear spaces and Concli (2012) expanded this idea [13].

Dawson, 1984 [15] proposed and, in 1988 [16], modified an approximate formula for determining power losses, obtained from the results of an experimental study of losses separately at the ends of a spur gear and at its periphery.

Pechersky et al. (1987) [33] developed a numerical model for locking a certain volume of oil-air mixture between gear and pinion teeth addendum and dedendum in engagement. It was determined that the speed of the oil-air mixture in gears with a larger module is greater.

The results of the Changenet experiment (2008) [8] showed that with the reduction in side clearance between a rotating gear and a fixed wall, the power losses are decreased due to hydrodynamic resistance. It was also found that the relative reduction in power losses caused by the presence of the side clearance does not depend on the speed of gear rotation and its geometrical parameters.

\section{PROBLEM STATEMENT}

Despite the relatively numerous experimental studies, there are only few published works on the development of mathematical models that describe the hydrodynamic processes in gears. There is no generic analytical model that integrates all types of losses

The purpose of this work is to develop a modern generalised methodology for calculating hydrodynamic power losses of highspeed gears.

In order to determine the integral characteristics of energy dissipation due to aero-hydrodynamic resistance in analytical form, a simplified mathematical model based on the following assumptions is proposed.

- aerodynamic drag in a gear tooth space is determined by the Coriolis force caused by the radial flow rate of the oil-air mixture during its rotation together with the toothed gear;

- additional sources of energy dissipation include the viscous friction of the oil-air mixture on the working surfaces and heads of teeth, the face surfaces of the gear and inhibition of the flow of the mixture in the clearance between a gear and gearbox;

- the radial speed of the oil-air mixture in the gear tooth spaces and the speed of rotation of a gear are constant;

- transient modes of relative flow of oil-air mixture (either laminar or turbulent mode) are absent;

- losses caused by bearings and sealings are relatively small and can be neglected.

\subsection{Mathematical simulation of power losses when immersing a gear in an oil bath}

Depending on the operating conditions, different methods of oil supply to parts and gear drive units are used. They are mainly lubrication by immersion into oil bath, spraying from the main oil bath and circulating-type oil supply.

In the general case, when lubricating the gear by immersion into the oil bath, the gears are affected by actions such as the force of aerodynamic resistance and the force of hydrodynamic resistance.

At a relative immersion depth $h_{i}=\frac{h_{i}}{r_{a i}} \leq 0$, the lubricating oil does not come into contact with the gear (circulating oil supply).

The immersion depth $h_{i} \geq 2$ corresponds to the case of complete immersion of the gear into the oil bath.

At a depth of $h_{i}=2$, the angle $\varphi_{i}=\pi$ and the lubricating surface at the ends of the gear is $A_{\text {wash }}=2 \cdot \pi \cdot r_{a i} \cdot b_{i}$. When $h_{i} \leq 0$, similar to the case of $h_{i}=2$, we can consider that the wheel is completely immersed, but in air. The force of hydrodynamic resistance is converted into the force of aerodynamic resistance.

The ratio of the aerodynamic and hydrodynamic resistance forces is determined by the oil level in the oil bath.

Power losses due to the action of the Coriolis force are caused by the presence of radial velocity of the oil-air mixture in the spaces of rotating gear. They were validated on the basis of the results of mathematical modelling of processes in the spaces of a rapidly rotating gear [42] and also by the experiment of Akin and Mross [2], among others.

For each gear, partially or fully immersed into the oil bath, the power spent to overcome the hydromechanical resistance can be represented as the sum of the following components:

$M_{a}=M_{k}+M_{v}+M_{f}$

where $M_{k}$ is the moment of the Coriolis force arising due to the radial movement of the oil in the tooth spaces of the rotating gear 
in newton-metres; $M_{v}$ is the moment of viscous friction forces on the periphery of the gear addendums in the oil bath, in newtonmetres; $M_{f}$ is the moment of viscous friction forces at the gear face end in the oil bath, in newton-metres.

\section{THE PROBLEM SOLUTION}

\subsection{Determination of hydrodynamic power losses due to Coriolis force action}

The Coriolis force $\mathrm{F}_{\mathrm{k}}$ that acts on the working surface of one of the gear teeth is determined by the formula

$F_{k}=m_{b m} \cdot a_{k}$

where $m_{b m}=\frac{m_{b m a x}+m_{b m i n}}{2}$ is the average mass of the oil in the gear tooth spaces, in kilograms; $m_{b m a x}$ is the mass of the oil in the tooth spaces at the time of its exit from the oil bath, in kilograms; $m_{b m i n}$ is the mass of the oil in the tooth spaces at the time of beginning of the gear immersion into the oil bath, in kilograms; $a_{k}$ is the Coriolis acceleration that occurs due to the movement of the oil-air mixture in the tooth spaces in the radial direction of a rotating gear, in metres per square second.

The Coriolis acceleration is determined by the formula

$a_{k}=2 \cdot \omega_{i}^{2} \cdot r_{i} \cdot \sin \alpha \cdot \cos \beta$

where $\beta$ is the angle of the tooth line inclination, in radians; $\alpha_{i}$ is the operating pressure angle at any point of the involute of radius $r_{i} ; \omega_{i}$ is the angular velocity; $r_{i}$ is the radius to any point on the tooth profile curve.

The average mass of the oil in a tooth space located in the oil bath can be determined by the following formula:

$m_{b m}=\frac{Q_{3} \cdot \Delta t}{2}$

where $Q_{3}$ is the mass consumption of the oil when filling the tooth spaces through the backlash area of the tooth immersed into the oil bath, in kilograms per second; $\Delta \mathrm{t}$ is the time period when a tooth space is in the oil bath, in seconds.

$\Delta t=\frac{\overrightarrow{A C}}{\omega_{i}}=\frac{2 \cdot \phi_{i} \cdot r_{i}}{\omega_{i}}=\frac{2 \cdot r_{i} \cdot \arccos \left(1-h_{i}\right)}{\omega_{i}}$

$\overline{\mathrm{AC}}$ is the arc length determined by the immersion depth of the gear in the oil bath; $h_{i}$ is the tooth height at any point of the tooth; $\varphi_{\mathrm{i}}$ is the angle of gear rotation in the process of meshing.

Mass consumption of the oil while filling the tooth spaces in the case of its immersion into the oil bath $Q_{3}$ depends on the end cross-sectional area of the tooth space, the actual speed of its filling with oil and the density of the oil:

$Q_{3}=A_{a} \cdot \rho_{m} \cdot V_{3}$

where $\rho_{\mathrm{m}}$ is the density of the lubricant at a specified temperature of the oil bath, in kilograms per cubic metre; $A_{a}=$ $\mathrm{S}_{\mathrm{bn}} \cdot \sum_{\mathrm{i}=1}^{2} \mathrm{y}_{\mathrm{i}}$ is the cross-sectional area of the tooth spaces in the axial direction, in cubic metres; $y_{i}$ is the backlash coefficient obtained by the experiment; $\mathrm{S}_{\mathrm{bn}}$ is the tooth cross-sectional area, in square metres; $V_{3}$ is the actual velocity of the filling of the tooth spaces by the axial flow of oil when the gear is immersed into the oil bath, in metres per second.
Then,

$m_{b m}=\frac{A_{a} \cdot \rho_{m} \cdot V_{3} \cdot r_{i} \cdot \arccos \left(1-h_{i}\right)}{\omega_{i}}$.

The magnitude of the velocity of filling of the tooth spaces in the axial direction is determined by Bernoulli's law:

$\rho_{m} \cdot \frac{V_{3}^{2}}{2}=p_{b}-p_{j}-p_{g}+p_{h}+\rho_{m} \cdot \frac{k_{0}^{2} \cdot V_{\tau}^{2}}{2}$,

where $\mathrm{p}_{\mathrm{b}}$ is the oil pressure in the tooth spaces due to the action of the friction forces, in megapascals; $p_{j}$ is the oil pressure in the tooth spaces due to centrifugal forces, in megapascals; $\mathrm{p}_{\mathrm{g}}$ is the oil pressure in the tooth spaces due to the action of gravity, in megapascals; $p_{h}$ is the hydrostatic pressure in the tooth spaces, in megapascals; $V_{\tau}=\omega \cdot r \cdot \sin \alpha \cdot \cos \beta$ is the velocity of the oil flow, which is displaced by the tooth profile from the tooth spaces in the radial direction, in metres per second; $\mathrm{k}_{\mathrm{o}}$ is the velocity coefficient, which depends on the shape of the oil flow from the tooth spaces of the gear.

Equation (8) describes the processes occurring in the tooth spaces that are immersed into the oil bath: the oil is ejected from the tooth spaces by gravitational and centrifugal forces and held in the tooth spaces by viscous and hydrostatic forces. But some of the oil is emitted in the radial direction at velocity $V_{i}$, and arrives axially at velocity $\mathrm{V}_{3}$.

If the relative addendum circle radius of the gear is $R_{a}=r_{a}$. $r_{i}$ and the relative dedendum circle radius $R_{b}=r_{f} \cdot r_{i}$, we get the relative pressure of the oil centrifugal forces of inertia:

$p_{j}=\frac{p_{j}}{\rho_{m} \cdot \omega_{i}^{2} \cdot r_{i}^{2}}=\frac{1}{2} \cdot\left(R_{a}^{2}-R_{b}^{2}\right)$,

where $r_{a}$ is the tip fillet radius; $r_{f}$ is the root fillet radius.

The area of the wetted surface is determined as

$A_{\text {wash }}=b \cdot r_{i}^{2} \cdot\left(\tan ^{2} \alpha_{a}-\tan ^{2} \alpha_{f}\right) \cdot \cos \alpha$

Taking into account that the Reynolds number is $R e=\frac{\omega_{\mathrm{i}} \cdot \mathrm{r}_{\mathrm{i}}^{2}}{v_{\mathrm{m}}}$ the relative oil pressure in the tooth spaces due to viscous friction forces is calculated as

$p_{b}=\frac{p_{b}}{\rho_{m} \cdot \omega_{i}^{2} \cdot r_{i}^{2}}=\frac{V_{\tau}^{1.5} \cdot\left(\tan ^{2} \alpha_{a}-\tan ^{2} \alpha_{f}\right) \cdot \cos \alpha}{\varphi_{i}^{1.5} \cdot A_{i} \cdot \sqrt{3 \cdot \operatorname{Re}}}$

where

$\phi_{i}=\left(\frac{V_{\tau}}{\varphi_{i}}\right)^{1.5} \cdot \frac{\left(\tan ^{2} \alpha_{a}-\tan ^{2} \alpha_{f}\right) \cdot \cos \alpha}{R_{a} \cdot \sqrt{3}}=$

$=\left(\frac{\sin \alpha \cdot \cos \beta}{\varphi_{i}}\right)^{1.5} \times \frac{\left(\tan ^{2} \alpha_{a}-\tan ^{2} \alpha_{f}\right) \cdot \cos \alpha}{R_{a} \cdot \sqrt{3}}$.

The relative pressure of the gravitational forces is

$p_{g}=\frac{\left(R_{a}-R_{b}\right) \cdot r_{i} \cdot g \cdot \rho_{m}}{\rho_{m} \cdot \omega_{i}^{2} \cdot r_{i}^{2}}=\frac{\left(R_{a}-R_{b}\right)}{F_{r}}$

where $F_{r}=\frac{\omega_{i}^{2} \cdot r_{i}}{g}$ is Froude's number; $g$ is the acceleration due to gravity.

The relative hydrostatic pressure of the oil in the tooth spaces at the pitch circle is determined in the following way:

$p_{h}=\frac{r_{i} \cdot h_{i} \cdot g \cdot \rho_{m}}{\rho_{m} \cdot \omega_{i}^{2} \cdot r_{i}^{2}}=\frac{h_{i}}{F_{r}}$.

Substituting Eqs (9) and (11-13) into Eq. (8), we obtain the Bernoulli equation in the dimensionless form: 
$V_{3}^{2}=\left(R_{a}^{2}-R_{b}^{2}\right)+\frac{2}{F_{r}}\left(h_{i}-R_{a}-R_{b}\right)+\frac{2 \Phi_{i}}{\sqrt{\mathrm{Re}}}$

$+\left(k_{o} \cdot \sin \alpha \cdot \cos \beta\right)^{2}$

The dimensionless filling velocity of the tooth spaces immersed into the oil bath is

$\frac{V_{3}}{\omega_{i} \cdot r_{i}}=\mathrm{V}_{3}=k_{s} \times$

$\sqrt{\left(R_{a}^{2}-R_{b}^{2}\right)+\frac{2}{F_{r}}\left(h_{i}-R_{a}-R_{b}\right)+\frac{2 \Phi_{i}}{\sqrt{\mathrm{Re}}}+\left(k_{o} \cdot \sin \alpha \cdot \cos \beta\right)^{2}}$

where $\mathrm{k}_{\mathrm{s}}$ is the speed coefficient of the end face section of the gear tooth spaces $\left(\mathrm{k}_{\mathrm{s}}=0.85\right.$ for absolutely sharp edges of teeth, $\mathrm{k}_{\mathrm{s}}=0.9$ in the case of additional processing of edges of teeth).

Then, we obtain

$Q_{3}=\frac{(\pi-4 \cdot x \cdot \tan \alpha)}{z} \cdot \frac{r_{i}^{3} \cdot\left(R_{a}^{2}-R_{b}^{2}\right)}{2} \times$

$\times \sum_{i=1}^{2} y_{i} \cdot \rho_{m} \cdot \omega_{i} \cdot V_{3} \cdot \cos \beta$

and

$m_{b m}=\frac{\rho_{m} \cdot \mathrm{r}_{i}^{3} \cdot(\pi-4 \cdot x \cdot \tan \alpha) \cdot\left(R_{a}^{2}-R_{b}^{2}\right)}{2 \cdot z} \times$

$\times \frac{\sum_{i=1}^{2} y_{i} \cdot V_{3} \cdot \arccos \left(1-h_{i}\right) \cdot \cos \beta}{2 \cdot z}=$

$=\frac{\rho_{m} \cdot \mathrm{r}_{i}^{3} \cdot m_{b m}}{2 \cdot z}$

where $y_{i}=\frac{4 \cdot R_{b} \cdot \delta_{i}}{\left(R_{a}^{2}-R_{b}^{2}\right)}$ is the coefficient of backlash area, which is considered as the ratio of the radial clearance area of one tooth to the area of the tooth spaces.

The Coriolis force is

$F_{k}=\rho_{m} \cdot r_{i}^{4} \cdot \frac{m_{b m}}{z_{i}} \cdot \omega_{\mathrm{i}}^{2} \cdot \sin \alpha \cdot \cos \beta$

The Coriolis force moment in the case where the gear is immersed into the oil bath (torque of the resistance of gear) is:

$M_{k}=\frac{\arccos \left(1-h_{i}\right) \cdot z_{i}}{\pi} \cdot F_{k} \cdot r_{i} ;$

$M_{k}=\frac{\rho_{m} \cdot \omega_{i}^{2} \cdot r_{i}^{5}}{\pi} \cdot(\pi-4 \cdot x \cdot \tan \alpha) \cdot\left(R_{a}^{2}-R_{b}^{2}\right) \times$

$\times \sum_{i=1}^{2} y_{i} \cdot V_{3} \cdot \arccos ^{2}\left(1-h_{i}\right) \cdot \sin \alpha \cdot \cos ^{2} \beta$ as

For a zero-toothed gear, expression (18) is partially simplified

$M_{k}=\rho_{m} \cdot \omega_{i}^{2} \cdot \mathrm{r}_{i}^{5} \cdot\left(R_{a}^{2}-R_{b}^{2}\right) \times$

$\times \sum_{i=1}^{2} y_{i} \cdot V_{3} \cdot \arccos ^{2}\left(1-h_{i}\right) \cdot \sin \alpha \cdot \cos ^{2} \beta$

When the zero-toothed gear is immersed into the oil bath, the dimensionless moment of the Coriolis force is

$C_{k}=2 \cdot\left(R_{a}^{2}-R_{b}^{2}\right) \cdot \frac{(\pi-4 \cdot x \cdot \tan \alpha)}{\pi} \times$

$\times \sum_{i=1}^{2} y_{i} \cdot V_{3} \cdot \arccos ^{2}\left(1-h_{i}\right) \cdot \sin \alpha \cdot \cos ^{2} \beta$

\subsection{Determination of losses due to viscosity friction at the periphery of the toothed gear}

A gearing, partially or fully immersed into the oil bath, is subject to the forces of hydrodynamic friction, both on the periphery of the gear and on the lateral surfaces of gears.

The boundary conditions for oil circulation along the periphery of the gear are $\mathrm{V}_{\text {out }}=\omega_{\mathrm{i}} \cdot \mathrm{r}_{\mathrm{ai}}$ when $\mathrm{r}=\mathrm{r}_{\mathrm{ai}}$; and $\mathrm{V}_{\text {out }}=0$ when $r \rightarrow \infty$; where $\omega_{\mathrm{i}}$ is the angular velocity of the gear and $r \in\left(r_{a i}, \infty\right)$. Solving Eq. (19) with the given boundary conditions, we obtain the flow velocity at the periphery of the gear as

$V_{\text {out }}=\frac{\omega_{i} \cdot r_{a i}^{2}}{r}$.

Then, at a given dynamic viscosity, the radial, axial and tangential components of the stress on the toothed gear periphery due to the gear rotation are determined as follows:

$\tau_{\text {out }}=2 \cdot \mu_{m} \cdot \frac{\partial V_{\text {out }}^{r}}{\partial r}=0$;

$\tau_{\text {out }}=2 \cdot \mu_{m} \cdot\left(\frac{1}{r} \frac{\partial V_{\text {out }}^{\tau}}{\partial \tau}+\frac{V_{\text {out }}^{r}}{r}\right)=0$;

$\tau_{\text {out }}=\mu_{m} \cdot r \cdot \frac{\partial}{\partial r}\left(\frac{V_{\text {out }}^{\tau}}{r}\right)+\frac{1}{r} \cdot \frac{\partial V_{o u t}^{r}}{\partial \tau}=-\frac{2 \cdot \mu_{m} \cdot \omega_{i} \cdot r_{a i}^{2}}{r^{2}}$.

It can be seen from Eqs (22-24) that only the tangential component of the stress at the gear periphery is not equal to zero. It follows from Eq. (24) that on the periphery of the toothed gear $r=r_{a i}$, the tangential stress is equal to $\tau_{\text {out }}=2 \cdot \mu_{\mathrm{m}} \cdot \omega_{\mathrm{i}}$ and the resistance force is equal to

$F_{\text {out }}=A_{\text {wash }} \cdot \tau_{\text {out }}=2 \cdot A_{\text {wash }} \cdot \mu_{m} \cdot \omega_{i}$,

where $A_{\text {wash }}=2 \cdot \phi_{\mathrm{i}} \cdot \mathrm{r}_{\mathrm{ai}} \cdot \mathrm{b}_{\mathrm{i}}$ is the wetted surface area, in square metres.

The ultimate torque of the hydrodynamic resistance on the periphery of a single gear is determined as follows:

$M_{\text {out }}=F_{\text {out }} \cdot r_{a i}=4 \cdot \mu_{m} \cdot b_{i} \cdot r_{a i}^{2} \cdot \omega_{i} \cdot \phi_{i}$;

$M_{\text {out }}=\frac{4 \cdot \mu_{m} \cdot R_{a}^{2} \cdot b_{i} \cdot r_{a i}^{5} \cdot \omega_{i}^{2} \cdot \phi_{i} \cdot \rho_{m}}{\rho_{m} \cdot \omega_{i}^{2} \cdot r_{i}^{2}}=\frac{4 \cdot R_{a}^{2} \cdot \rho_{m} \cdot b_{i} \cdot r_{a i}^{5} \cdot \omega_{i}^{2} \cdot \phi_{\mathrm{i}}^{2}}{\operatorname{Re}}$.

Substituting the angle $\phi_{\mathrm{i}}=\arccos \left(1-\mathrm{h}_{\mathrm{i}}\right)$, the dimensionless torque of toothed gear rotation resistance due to viscosity friction at the tooth periphery equals

$C_{\text {out }}=\frac{M_{\text {out }}}{\rho_{m} \cdot r_{i}^{5} \cdot \omega_{i}^{2}}=\frac{8 \cdot R_{a}^{3} \cdot b_{i} \cdot \arccos \left(1-h_{i}\right)}{\operatorname{Re}}$.

\subsection{Determination of viscosity friction at the face end of the toothed gear}

The dimensional torque of hydraulic resistance due to viscous friction of oil under laminar flow conditions is

$$
\begin{aligned}
& C_{M}^{\operatorname{lam}}=\frac{\sqrt{v_{m}}}{\sqrt{3 \cdot l_{*} \cdot \omega_{i} \cdot r_{i}^{2}}}=\frac{1}{\sqrt{3 \cdot l_{*} \cdot \operatorname{Re}}}= \\
& =\frac{1}{\sqrt{6 \cdot A_{i} \cdot \sqrt{h_{i} \cdot\left(2-h_{i}\right)} \cdot \operatorname{Re}}}
\end{aligned},
$$

where $l_{*}=2 r_{a i} \sqrt{h_{i}\left(2-h_{i}\right)}=2 A_{i} r_{i} \times \sqrt{h_{i}\left(2-h_{i}\right)}$ is the characteristic linear size, in metres.

The hydraulic resistance force due to friction of the oil at the face surface of the gear under laminar flow conditions is found as

$$
\begin{aligned}
& F_{T}^{\text {lam }}=\rho_{m} \cdot A_{i}^{2} \cdot \omega_{i}^{2} \cdot r_{i}^{4} \times \\
& \times \frac{\left[\arccos \left(1-h_{i}\right)-\sqrt{h_{i} \cdot\left(2-h_{i}\right)} \cdot\left(1-h_{i}\right)\right]}{\sqrt{6 \cdot A_{i} \cdot \sqrt{h_{i} \cdot\left(2-h_{i}\right)} \cdot \operatorname{Re}}} .
\end{aligned}
$$

The torque of the hydraulic resistance due to the friction of the 
oil at the face surface of the toothed gear under laminar flow conditions is defined as $\mathrm{M}_{\mathrm{T}}^{\mathrm{lam}}=\mathrm{F}_{\mathrm{T}}^{\mathrm{lam}} \cdot \mathrm{r}_{\mathrm{i}}$;

$M_{T}^{\text {lam }}=\rho_{m} \cdot A_{i}^{2} \cdot \omega_{i}^{2} \cdot r_{i}^{5} \times$

$\times \frac{\left[\arccos \left(1-h_{i}\right)-\sqrt{h_{i} \cdot\left(2-h_{i}\right)} \cdot\left(1-h_{i}\right)\right]}{\sqrt{6 \cdot A_{i} \cdot \sqrt{h_{i} \cdot\left(2-h_{i}\right)} \cdot \operatorname{Re}}}$.

The dimensionless torque of hydraulic resistance due to oil friction at the face surface of the toothed gear under laminar flow conditions is

$C_{T}^{l a m}=\frac{M_{T}^{l a m}}{0.5 \cdot \rho_{m} \cdot \omega_{i}^{2} \cdot r_{i}^{5}}=$

$=\frac{2 \cdot A_{\mathrm{i}}^{2} \cdot\left[\arccos \left(1-h_{i}\right)-\sqrt{h_{i} \cdot\left(2-h_{i}\right)} \cdot\left(1-h_{i}\right)\right]}{\sqrt{6 \cdot A_{i} \cdot \sqrt{h_{i} \cdot\left(2-h_{i}\right)} \cdot \operatorname{Re}}} \cdot$

For turbulent flow mode,

$C_{M}^{\text {turb }}=0.0276 \cdot\left(\frac{v_{m}}{l \cdot \omega_{i} \cdot r_{i}}\right)^{\frac{1}{7}}=$

$=\frac{0.0276}{\sqrt[7]{2 \cdot A_{i} \cdot \sqrt{h_{i} \cdot\left(2-h_{i}\right)} \cdot \operatorname{Re}}}$

The hydraulic resistance due to friction of the oil at the face surface of the gear under turbulent flow conditions is determined similar to Eq. (29):

$F_{T}^{\text {turb }}=0.5 \cdot \rho_{m} \cdot \omega_{i}^{2} \cdot r_{i}^{2} \cdot 2 \cdot A_{\text {wash }} \cdot C_{M}^{\text {turb }}$.

Substituting Eqs (10) and (32) into Eq. (33), the moment of friction viscosity forces in turbulent motion is

$M_{T}^{\text {turb }}=F_{T}^{\text {turb }} \cdot r_{i}=\rho_{m} \cdot A_{i}^{2} \cdot \omega_{i}^{2} \cdot r_{i}^{5} \times$
$\times \frac{0.0276 \cdot\left[\arccos \left(1-h_{i}\right)-\sqrt{h_{i} \cdot\left(2-h_{i}\right)} \cdot\left(1-h_{i}\right)\right]}{\sqrt[7]{2 \cdot A_{i} \cdot \sqrt{h_{i} \cdot\left(2-h_{i}\right)} \cdot \operatorname{Re}}}$.

The dimensionless torque of hydraulic resistance due to oil friction at the face surface of the toothed gear under turbulent flow conditions is

$$
\begin{aligned}
& C_{T}^{\text {turb }}=\frac{M_{T}^{\text {turb }}}{0.5 \cdot \rho_{m} \cdot \omega_{i}^{2} \cdot r_{i}^{5}}= \\
& =A_{i}^{2} \cdot \frac{0.0276 \cdot\left[\arccos \left(1-h_{i}\right)-\sqrt{h_{i} \cdot\left(2-h_{i}\right)} \cdot\left(1-h_{i}\right)\right]}{\sqrt[7]{2 \cdot A_{i} \cdot \sqrt{h_{i} \cdot\left(2-h_{i}\right)} \cdot \operatorname{Re}}}
\end{aligned}
$$

The total torque of the hydromechanical resistance of the gear immersed into the oil bath is determined as follows:

$M=0.5 \cdot \rho_{m} \cdot \omega_{i}^{2} \cdot r_{i}^{5} \cdot\left(C_{k}+C_{T}+C_{\text {out }}\right)$.

Power loss due to the hydrodynamic resistance to rotating gear immersed into the oil bath is

$P=0.5 \cdot \rho_{m} \cdot \omega_{i}^{3} \cdot r_{i}^{5} \cdot\left(C_{k}+C_{T}+C_{\text {out }}\right)$.

Based on the obtained formulas, the mathematical modelling in the symbolic module MathCAD 12 was carried out (Stavitskiy, 2011, 2012 [38], [39], [40], [41], [42]), with variable parameters such as the kinematic viscosity $v_{\mathrm{m}}$ and density of the lubricant at a specified temperature of the oil bath $\rho_{m}$ :

$\log \left[\log \left(v_{\mathrm{m}}+0.6\right)\right]=\mathrm{A} \cdot \log \mathrm{T}+\mathrm{B}$,

where $T$ is the oil temperature in kelvins, and $A$ and $B$ are constant coefficients.

Figure 1 represents the analysis of the calculation results of the power losses due to the action of hydraulic resistance forces
(37) and the experimental studies by Blok, 1962 [5], in which the research was carried out with several gears, the hydromechanical parameters of which were varied in the following ranges: module ranged from $1.5 \mathrm{~mm}$ to $5 \mathrm{~mm}$; the angle of the tooth line inclination $\beta=25^{\circ}$; face width of the gear ring ranged from 14 to 24 $\mathrm{mm}$; and number of teeth ranged from 20 to 102) (Table 1). In Fig. 1 , the relative depth of gear immersion in the oil bath is 0.55 . It allows predicting the influence of the geometrical parameters of the gearing on the hydrodynamic power losses.

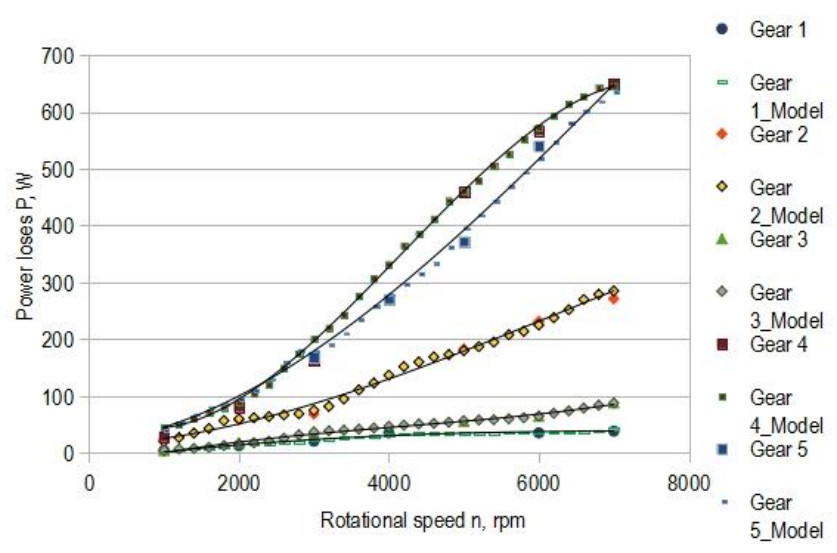

Fig. 1. Comparison of calculation results of the power losses due to hydrodynamic resistance to rotation of a toothed gear in the oil bath with experimental data

Tab. 1. Hydromechanical parameters of the gears

\begin{tabular}{|c|c|c|c|c|c|c|c|}
\hline & Gear 1 & Gear 2 & $\begin{array}{c}\text { Gear } \\
\text { 2_Model }\end{array}$ & Gear 3 & $\begin{array}{c}\text { Gear } \\
\text { 4 }\end{array}$ & $\begin{array}{c}\text { Gear } \\
\text { 4_Model }\end{array}$ & Gear 5 \\
\hline $\begin{array}{c}\text { Nominal } \\
\text { pitch circle } \\
\text { diameter, mm }\end{array}$ & 96 & 153 & 153 & 90 & 159 & 159 & 100 \\
\hline $\begin{array}{c}\text { Face width, } \\
\text { mm }\end{array}$ & 14 & 14 & 14 & 24 & 24 & 24 & 24 \\
\hline $\begin{array}{c}\text { Module, mm } \\
\text { Number of } \\
\text { teeth, } \mathrm{n}\end{array}$ & 1,5 & 1,5 & 1,5 & 3 & 3 & 3 & 5 \\
\hline
\end{tabular}

\section{DISCUSSION}

Comparative analyses of the computational and experimental results yielded the following observations:

- The proposed method of calculating power losses due to hydromechanical resistance of the oil bath to rotation of the gear gives results with an error in the range of $1 \%-9 \%$ in relation to the experimental data;

- The change in hydrodynamic losses with a change in gear speed is practically subject to the law of the cubic parabola, but up to a certain speed (in Fig. 1, it is about 4,000 rev/min). A further increase in rotational speed leads to a decrease in the amount of oil in the space (disturbed mass balance: more oil is ejected from the space by centrifugal forces than the amount of oil entering the space through the space ends);

- At significant rotational speeds (in Fig. 1, it is from $5,000 \mathrm{rev} / \mathrm{min}$ to $7,000 \mathrm{rev} / \mathrm{min}$ ), the amount of oil in the spaces decreases, and the power losses due to the hydrodynamic resistance in the oil bath, accordingly, are slightly reduced. Theoretical studies have made it possible to determine the 
presence of two modes of oil motion in the tooth spaces of gears, which are characterised by the ratio of centrifugal, gravitational, hydrostatic, viscous and Coriolis forces.

\section{CONCLUSIONS}

When changing the face clearance from zero to the critical value, the power loss due to the hydrodynamic resistance of the toothed gear immersed into the oil bath is always less than similar losses, if the face clearance is greater than the critical value.

The dependence calculation Eq. (37) not only takes into account the influence of the geometrical parameters of the toothed gears immersed into the oil bath but also the structural characteristics, such as the depth of the toothed gear immersion and the face clearance between the casing walls and the rotating gear.

In order to determine the integral characteristics of energy dissipation and to develop a further engineering method for evaluating the energy efficiency of gearings, a mathematical model of the oil behaviour in the tooth spaces of rotating gears immersed into an oil bath has been developed.

The condition of the gear's maximum rotational speed at which lubrication by immersion into the oil bath becomes ineffective is established and the scheme of circulating greasing is found to be necessary.

Satisfactory coincidence of the theoretical and experimental results allows recommending the received analytical dependencies for practical calculations of high-speed gears.

\section{Notation}

$b_{i}$ - effective face width

$h_{i}$ - tooth height at any point of the tooth

$\phi_{i}$ - angle determined by the relative level of the oil bath

$m$ - module of the gearing

$r_{i}$ - radius to any point on the tooth profile curve

$x$ - profile offset factor

$z_{i}$ - number of teeth

$g$ - acceleration due to gravity

$\alpha_{i}$-operating pressure angle at any point of the involute of radius $r_{i}$

$\alpha_{a}$ - pressure angle for addendum circle

$\alpha_{f}$ - pressure angle for dedendum circle

$\delta_{i}$ - inclined angle of the meshing line of directrixes with respect to the pinion axis of rotation

$\rho_{\mathrm{m}}$ - the density of the lubricant

$\mu_{m}$ - dynamic viscosity

$v_{m}$ - kinematic viscosity

$\varphi_{i}$ - angle of gear rotation in the process of meshing

$r_{a}-$ tip fillet radius

$r_{f}$ - root fillet radius

$\omega_{i}$ - angular velocity

ð - thickness of the boundary layer

\section{REFERENCES}

1. Ahsan SN, Aureli M. Minimization of Hydrodynamic Power Losses in Oscillating Submerged Structures by a Novel Shape-Morphing Strategy. Volume 2: Mechatronics; Mechatronics and Controls in Advanced Manufacturing; Modeling and Control of Automotive Systems and Combustion Engines; Modeling and Validation; Motion and Vibration Control Applications; Multi-Agent and Networked Systems; Path Planning and Motion Control; Robot Manipulators; Sensors and Actuators; Tracking Control Systems; Uncertain Systems and Robustness; Unmanned, Ground and Surface Robotics; Vehicle Dynamic Controls; Vehicle Dynamics and Traffic Control. 2016; 2: 1214.

2. Akin LS, Mross JJ. Theory for the Effect of Windage on the Lubricant Flow in the Tooth Spaces of Spur Gears. Journal of Engineering for Industry. 1975;97(4):1266-1272.

3. Amani A, Spitas C, Spitas V. Generalised non-dimensional multiparametric involute spur gear design model considering manufacturability and geometrical compatibility. Mechanism and Machine Theory. 2017;109:250-277.

4. Barone S. Gear Geometric Design by B-Spline Curve Fitting and Sweep Surface Modelling. Engineering with Computers. 2001;17(1):66-74.

5. Blok H. Hydrodynamic effects on friction in rolling with slippage. Biolwelle Joseph B. Rolling contact phenomena. Amsterdam: Elsevier; 1962.

6. Bolotovskiy I, Gurev B, Smirnov V, Shenderey B. Cylindrical involute gears in external gearing. Moskva: Mashinostroenie (in Russian); 1974.

7. Changenet $C$, Velex P. A Model for the Prediction of Churning Losses in Geared Transmissions-Preliminary Results. Journal of Mechanical Design. 2006;129(1):128-33.

8. Changenet $C$, Velex $P$. Housing Influence on Churning Losses in Geared Transmissions. Journal of Mechanical Design. 2008;130(6).

9. Changenet $C$, Oviedo-Marlot X, Velex P. Power Loss Predictions in Geared Transmissions Using Thermal Networks-Applications to a Six-Speed Manual Gearbox. Journal of Mechanical Design. 2005;128(3):618-625.

10. Chen C-F, Tsay C-B. Tooth profile design for the manufacture of helical gear sets with small numbers of teeth. International Journal of Machine Tools and Manufacture. 2005;45(12):1531-1541.

11. Chen G, Li H, Liu Y. Double-arc harmonic gear profile design and meshing analysis for multi-section conjugation. Advances in Mechanical Engineering. 2019;11(5):168781401985065.

12. Chen H, Zhang X, Cai X, Ju Z, Qu C, Shi D. Computerized design, generation and simulation of meshing and contact of hyperboloidaltype normal circular-arc gears. Mechanism and Machine Theory. 2016:96:127-145

13. Concli F, Gorla C. Analysis of the Oil Squeezing Power Losses of a Spur Gear Pair by Mean of CFD Simulations. Volume 2: Applied Fluid Mechanics; Electromechanical Systems and Mechatronics; Advanced Energy Systems; Thermal Engineering; Human Factors and Cognitive Engineering. 2012: 1-8.

14. Daily JW, Nece RE. Chamber Dimension Effects on Induced Flow and Frictional Resistance of Enclosed Rotating Disks. Journal of Basic Engineering. 1960;82(1):217-230.

15. Dawson PH. Windage Loss in Larger High-Speed Gears. Proceedings of the Institution of Mechanical Engineers, Part A: Power and Process Engineering. 1984;198(1):51-59.

16. Dawson P. High speed gear windage GEC Review. GEC Review. 1988:43(3):164-167.

17. Sheng W, Li Z, Zhang H, Zhu R. Geometry and design of spur gear drive associated with low sliding ratio. Advances in Mechanical Engineering. 2021;13(4):168781402110125. 
18. Franulovic M, Markovic K, Vrcan Z, Soban M. Experimental and analytical investigation of the influence of pitch deviations on the loading capacity of HCR spur gears. Mechanism and Machine Theory. 2017:117:96-113.

19. Heingartner $P, M b a D$. Determination power losses in the helical gear mesh. Gear technology. 2005;22(5):32-37.

20. Hlebanja G. S-Gears for Wind Power Turbine Operating Conditions. Machine Design. 2012;4(3):123-130.

21. Gao Q, Ye J, Liu C. Design and modeling of noncircular gear with curvature radius function. Journal of Computational Methods in Sciences and Engineering. 2018;18(3):683-689.

22. loselevich G.B. Machine parts. Moskva: Mashinostroenie (in Russian); 1988.

23. Kapelevich A. Geometry and design of involute spur gears with asymmetric teeth. Mechanism and Machine Theory. 2000;35(1):117130.

24. Karpov O, Nosko P, Fil P, Nosko O, Olofsson U. Prevention of resonance oscillations in gear mechanisms using non-circular gears. Mechanism and Machine Theory. 2017;114:1-10.

25. Senthil Kumar V, Muni D, Muthuveerappan G. Optimization of asymmetric spur gear drives to improve the bending load capacity. Mechanism and Machine Theory. 2008;43(7):829-858.

26. Lechner G, Naunheimer H. Automotive TransmissionsFundamentals, Selection, Design and Application. 1st ed. Berlin: Springer; 1999.

27. Litvin F. Gear theory. Moskva: Nauka (in Russian); 1968

28. Litvin F, Lu J. Computerized simulation of generation, meshing and contact of double circular-arc helical gears. Mathematical and Computer Modelling. 1993;18(5):31-47.

29. Litvin F, Lu J. Computerized design and generation of double circular-arc helical gears with low transmission errors. Computer Methods in Applied Mechanics and Engineering. 1995;127(1):57-86.

30. Litvin FL, Fuentes A, Zanzi C, Pontiggia M. Design, generation, and stress analysis of two versions of geometry of face-gear drives. Mechanism and Machine Theory. 2002;37(10):1179-1211.

31. Mann RW, Marston CH. Friction Drag on Bladed Disks in Housings as a Function of Reynolds Number, Axial and Radial Clearance, and Blade Aspect Ratio and Solidity. Journal of Basic Engineering. 1961;83(4):719-723.

32. Niemann G, Winter H. Maschinenelemente. 2nd ed. Berlin (in German): Springer; 2003. (Band 2: Getriebeallgemein, Zahnradgetriebe - Grundlagen, Stirnradgetriebe).

33. Pechersky M. An analysis of fluid flow between meshing spur gear teeth. MS thesis, Pennsylvania State University, State College, PA. 1987.

34. Polly J, Talbot D, Kahraman A, Singh A, Xu H. An Experimental Investigation of Churning Power Losses of a Gearbox. Journal of Tribology. 2018;140(3): 031102.

35. Reshetov D. Detali mashin. Moskva: Mashinostroenie (in Russian).; 1989.

36. Seetharaman S, Kahraman A, Moorhead MD, Petry-Johnson TT. Oil Churning Power Losses of a Gear Pair: Experiments and Model Validation. Journal of Tribology. 2009;131(2):1-9.

37. Shishov $V$, Pankratov $D$, Muhovatyiy $O$. The evaluation criteria of efficiency gearing transmission. Visnik NTU KHPI (in Russian). 2001;12:27-33.

38. Stavitskiy V, Nosko P. Opredeleniye mekhanicheskogo kpd v zubchatom zatseplenii $s$ uchetom usloviy ekspluatatsii. Vestnik NTU «KHPI» (in Russian). 2011;51:152-164.

39. Stavitskiy V, Nosko P. Opredeleniye koeffitsiyenta poter' moshchnosti vsledstviye szhatiya maslovozdushnoy smesi mezhdu zub'yami tsilindricheskikh peredach. Vísnik Skhídnoukr. nats. u-tu ím. V. Dalya (in Russian). 2011;5(2):313-318.

40. Stavitskiy V, Nosko P. Gidrodinamicheskoye soprotivleniye v vysokoskorostnykh zubchatykh peredachakh, Progresivní tekhnologií i sistemi mashinobuduvannya. Mízhnarodniy zb. naukovikh prats' (in Russian). 2012:43:278-85.
41. Stavitskiy V, Nosko P, Likhodeyev S. Analiz sostavlyayushchikh poter' moshchnosti vsledstviye aerodinamicheskogo soprotivleniya vrashcheniyu zubchatykh koles, Progresivní tekhnologí í sistemi mashinobuduvannya. Mizhnar. zb. naukovikh prats' (in Russian). 2011:41:297-302.

42. Stavitskiy V, Nosko P, Fil P. Energeticheskaya effektivnost' vysokoskorostnyh zubchatyh peredach. Luhansk: vydavnytstvo SNU im. Dalia (in Russian); 2013.

43. Tkach P, Nosko P, Boyko G, Bashta O, Bashta A. Design of worm gears with optimal geometric parameters based on minimization of losses in gearing. Problems of Friction and Wear. 2018;1(78):75-84.

44. Tkach P, Nosko P, Bashta O, Boyko G, Tsybrii I, Gerasimova O. Gearing with increased teeth wear resistance. Problems of Friction and Wear. 2018;2(79):86-92.

45. Zhuravlev G. Evaluation of the Hertz solution applicability in problems of the gears teeth contact. Mezhdunar. konf. Tehn. Mashinostroeniya (in Russian). 2001.

46. Zhou X, Walker P, Zhang N, Zhu B, Ruan J. Study of Power Losses in a Two-Speed Dual Clutch Transmission. SAE Technical Paper Series. 2014:1799.

Oleksandr Bashta: ID https://orcid.org/0000-0001-7914-897X

Pavlo Nosko: iD https://orcid.org/0000-0003-4792-6460

Yurii Tsybrii: iD https://orcid.org/0000-0002-7444-6035 